\title{
La Orbita Poética de Jorge Carrera Andrade
}

$E^{N}$ su antología intitulada Registro del mundo, 1 que abarca el espacio cronológico comprendido entre los años 1922 y 1939, nos entrega y resume Jorge Carrera Andrade, su primera gran órbita poética.

Estamos ante un suceso lírico ya maduro y pleno de sugerencias para quienes siguen, paso a paso, la evolución de la poesía moderna en América del Sur, por cuanto Carrera Andrade, tanto por su ecuación étnica como espiritual, es un mestizo genuino que, pese a sus prolongadas travesías por el mundo, siempre se ha expresado en la modalidad poética que corresponde a un hombre del Pacífico americano. Aun en los poemas escritos en su residencia de Yokohama, donde la naturaleza y la milenaria tradición japonesa le acogen :

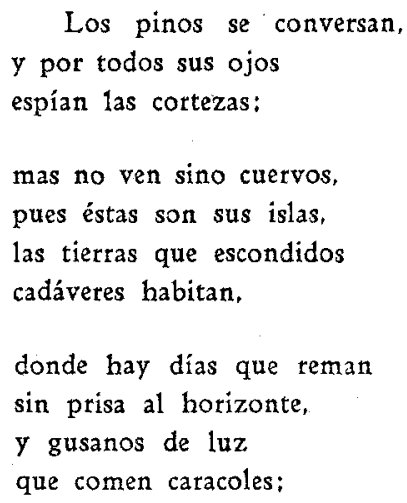




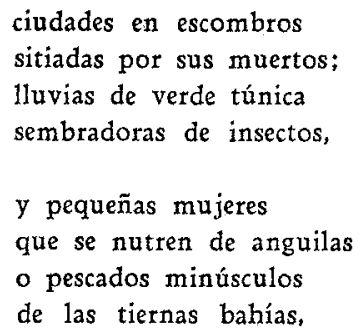

("Islas $\sin$ nombre")

siempre está presente su sangre y la técnica que adquirió a la luz de su Ecuador natal:

La naranja es el día o la mejilla fresca, sorbo de claridad, copa del clima;

la pera ahonda sus heridas de agua con memoria de témpano y agujas de delicia y los melocotones acumulan su rubio material de alegría.

("Régimen de frutas")

En los modernos poetas españoles tales como Jorge Guillén, Luis Cernuda, Luis Rosales, Rafael Alberti, Pedro Salinas, Vicente Aleixandre, la poesía se da como una entidad espiritual de fuerza centrífuga que va de lo íntimo, del yo del poeta hacia el mundo externo. Es flecha personalísima que se clava en cualquier objeto del orbe real. Es así como Luis Cernuda, en el apogeo de su lengua, escribe:

\section{Yo fui}

Columna atdiente, luna de primavera.

Mar dorado, ojos grandes.

Busqué lo que pensaba;

Pensé, como al amanecer en sueño lánguido,

Lo que pinta el deseo en días adolescentes.

Canté, subí,

Fuí luz un día

Arrastrado en la llama. 
Como un golpe de viento
Que deshace la sombra,
Cai en lo negro.
En et mundo insaciable.

He sido. 2

Pero en América, sucede lo contrario. El poeta integra la poesía partiendo de la naturaleza. En tal virtud, Pablo Neruda - genuino intérprete de esta modalidad - ha llegado a decirnos, en un estilo hecho de largos y rituales períodos, que es ella quien le ha impuesto a su obra un determinado género de tristeza:

Loros, estrellas, y además el sol artificial y una brusca humedad, hicieron nacer en mí un gusto ensimismado por la tierra y cuanta cosa la cubria, y una satisfacción de casa vieja por sus murciélagos, una delicadeza de mujer desnuda por sus uñas, dispusieron en mí como de armas débiles y tenaces de mis facultades vergonzosas, y la melancolía puso su estría en mi tejido, y la carta de amor, pálida de papel y temor, sustrajo su araña trémula que apenas teje y sin cesar desteje y teje. Naturalmente, de la luz lunar, de su circunstancial prolongación, y más aún, de su eje frío, que los pájaros (golondrinas, ocas) no pueden pisar ni en los delirios de la emigración, de su piel azul, lisa, delgada y sin albajas, caí hacia el duelo, y esa substancia a la vez nocturna y marítima, me hacía alterar y padecer, y esas aguas subcelestes degradaban mi energía y lo comercial de mi disposición. 3

A pesar "de lo comercial de su disposición", cónsul de Chile en un puerto de Oriente, el poeta reconoce que posee, que es "un sujeto de sangre especial", al cual la naturaleza le hiere con todos sus espejos. Que la selva formidable del Sur de Chile, ya le ha abierto desmesuradamente los ojos por toda una existencia, asignándole una determinada categoría poética que, cualquiera que sea su residencia en la tierra, será apta para su sangre de mestizo, de sudamericano cabal.

Tal es la ley a que está sujeto este equipo de poetas en el cual tiene una cátedra señalada Jorge Carrera Andrade; una ley que podríamos llamar "cósmica", en la que el poeta integra su poesía partiendo de la naturaleza y en donde su "yo" queda, como subordinado o pospuesto por aquélla. 
En determinadas circunstancias esta ley se verifica como una embriaguez, como un hálito en el cual el artista sólo se deja llevar y la naturaleza cae en su poesía, como en una cámara obscura:

Arbol de cacao,

arcángel preceptor del loro verde.

Docencia de frescura

en la tierra caliente.

Adición de colores, sustracción de sonidos,

cifra total de sombra.

Con una rocación celeste, dictas

tus lecciones de aroma.

("Arbol de cacao")

Aun en los últimos poemas que ha escrito Jorge Carrera Andrade, a partir de su libro Pais secreto ('Tokio, 1940), en donde una fuerza intima, una potencia subjetiva tiende a rebelarse para inaugurar un género distinto, se percibe la acumulación de objetos, la marea externa que forcejea sin cesar. En una electrizada descripción de la mujer, plena de Trópico y tensión, nos asegura que su estatua es la siguiente:

Tus cabellos son la muerte en el trópico, las hormigas gigantes.

Tus cabellos voraces como el incendio o el naufragio

a orillas de tu rostro con frutas y agua fresca.

Tu garganta es un árbitro

que separa a dos desnudos atletas.

Tus brazos son dos nadadores friolentos

$y$ en tus manos se mueven dos patrullas que te escoltan y sirven.

En tus senos hay una balanza que tiembla.

Se duerme a la redonda de tu vientre un remanso

girando hacia el remolino de tu ombligo.

En tu cintura hay una gacela.

En tu grupa, un caballo.

En tus muslos, dos alfanges y dos tigres que se desperezan.

Tus piernas son dos rutas que conducen

a dos plazas gemelas,

$y$ en tus pies se alinean diez arqueros

$\mathrm{y}$ hay dos peces, dos hongos y dos lenguas.

("Zona minada, 2") 
Aunque parezca inextricable, esta dificultosa evasión del poeta del mundo externo hacia su yo, hacia los sótanos de su conciencia, ya es visible en su libro El tiempo manual. Desorientado, encandilado por innumerables viajes y ciudades, empieza a pulsar las cuerdas intensamente españolas de su ánima y arguye:

Todo es apariencia, signo, tránsito.

El mundo es uno mismo, a pesar de sus formas.

La misma soledad hospedada en los huesos

y la misma afirmación proletaria

de las hornillas callejeras para calentar castañas.

("III clase")

Luego, es el tiempo el fantasma que se cuela, de rondón, por su lengua, como un hálito frío que viene a sorprenderle, a él, poeta fosforescente y siempre embriagado por el Trópico y las apariencias del mundo. En un principio, sólo constata su curso:

Los años van sin prisa enredando sus liquenes y el recuerdo es apenas un nenúfar

que asoma entre dos aguas

su rostro de ahogado.

("Biografía para.uso de los pájaros")

Después, profundiza en su esencia, le parece que pudiese medirlo, se familiariza con su sustancia:

Todo gesto humano, el tiempo

lo va copiando sin fin

en su avenida de espejos...

("Costumbre")

Finalmente, constata que el tiempo, como una ola, le va carcomiendo su morada; constata que es el fantasma inmanente capaz de ponerle en jaque, de llevar a su sangre una perpetua zozobra. Reúne inequívocos signos y aun, con un sentido sumamente oriental, llega a decirnos "que se pasa los minutos esperando: 
el derrumbre del muro, la llegada del rayo, el correo celeste con la final noticia, la sentencia que vuela en una avispa, la orden como un látigo de sangre dispersando en el viento una ceniza de ángeles".

("Morada terrestre")

$Y$, ahora, después de constatada la excepción cabría preguntarnos ¿qué obscura esencia, qué espíritu impele a este grupo de exaltados poetas que pueblan el Oeste de América del Sur y cuya poesía tiene por eje una fuerza espiritual de orden centrípeto, o sea, que va del mundo externo al ánima del artista? 4

Aunque se trata de una entidad de suyo delicada, es indudable que este problema tiene su clave en la sangre. Cuando se regustan stus obras, cuando se profundiza en la psicología de estos poetas, cuando se palpan sus efigies y sus modales, se supone, sin género de dudas, que hay en sus plasmas sanguíneos una franja de sangre india. No es raro, que sean éllos quienes se encarguen de negar rotundamente esta afirmación. Sobre el particular, Gabriela Mistral, a1 hacer el elogio de los "Tres cantos materiales" de Neruda, nos dice: "Neruda se estima blanco puro, al igual del mestizo común que, por su cultura europea, olvida fabulosamente su doble manadero. Los amigos españoles de Neruda sonríen cariñosamente a su convicción ingenua". 5 En cuanto a Jorge Carrera Andrade, es muy posible que no la abrigue. Sutil biógrafo de los espejos y las alcobas, más de una vez habrá meditado en sus ojos ligeramente oblicuos, en su porte oriental, en su instintiva habilidad para conducir el hai-kai.

Sin duda, hay en nosotros, hay en nuestra calidad de mestizos, un ojo y ciertas potencias bárbaras para las cuales la naturaleza tiene un sentido mágico. Un sentido que se traduce en un verdadero júbilo ritual. Un júbilo todavía no perturbado en nuestra costa del Pacífico, por la abrumadora técnica europea; un júbilo multiplicado aun por la exuberancia del Trópico y la hermosura de los mares australes. Por otra parte, en dicha costa, esta fórmula racial hispano-india, no sólo aún se conserva intacta, sino que se perfecciona y ya muestra en éstos y en otros artistas, las primeras bases de una cultura definida, contrariamente a lo que sucede -salvo las excep- 
ciones relativas al folklore - en la Costa del Atlántico, donde la inmigración descontrolada ha barrido con toda posible unidad $\mathrm{y}$ ha impuesto al criollo una cultura que, como en la ley de los vasos comunicantes, guarda idénticos niveles con Europa.

Es natural que los vehículos de esta poesía que sigue un aliento y júbilo cósmicos, de esta poesía mimética por naturaleza, sean la metáfora, el ritmo y el metro libres.

En Carrera Andrade, esta ley se da con plenitud. En lo que concierne a la metáfora - vértebra y medula de su poesía- es un artillero habilísimo cuya imaginación golpea, sin tregua, en el blanco de su modalidad lírica, con acierto invariable.

Ortega y Gasset, después de hacer el elogio de la metáfora en estos términos: "La metáfora es probablemente la potencia más fértil que el hombre posee. Su eficiencia llega a tocar los confines de la taumaturgia y parece un trebejo de creación que Dios se dejó olvidado dentro de una de sus criaturas al tiempo de formarla, como el cirujano distraído se deja un instrumento en el vientre del operado", 6 nos dice - siguiendo cierta escuela de psicólogos alemanes- que una de las raíces de la metáfora está en el espíritu del "tabú": 7 "Ha habido una época en que fué el miedo la máxima inspiración humana, una edad dominada por el terror cósmico. Durante ella se siente la necesidad de evitar ciertas realidades que, por otra parte, son ineludibles". $8 \mathrm{Y}$ agrega, que esta figura literaria viene a llenar tal función. Pero, sin duda, la metáfora también tiene otras raíces y creo que este aspecto sólo cuadra muy remotamente a nuestro mestizo. Así, verbi-gracia, el tabú chileno que asigna al pan el atributo de ser la cara de Dios (muy propio de un país en realidad pobre y virttalmente rico, debido a lo mucho que cuesta extraer la riqueza) está, evidentemente, en el área antedicha. 9

Sin embargo, el problema ha apasionado a numerosos espiritus. En efecto, Paul Valéry considera a la metáfora como una "acrobacia espiritual", como un ejercicio que vendría a ser al entendimiento lo que es la danza al cuerpo; y el profesor Freud, con su teoría particularísima ha dedicado un volumen íntegro al estudio del chiste que, desde cierto punto de vista, tiene un mecanismo anímico semejante al de la metáfora, o sea, suplantación de un objeto por otro, existiendo - según sea una $\mathfrak{u}$ otra entidad - una agradable o bella desproporción. 
En el caso que nos ocupa, el uso de la metáfora -más propiamente, el tropo- está íntimamente relacionado con el júbilo de orden cósmico, con ese ojo bárbaro y recóndito que mora en la sangre de nuestra cultura. Es la principal manifestación de un mimetismo poético. En efecto, según mi modesto juicio, la metáfora en el hombre civilizado, no es sino una potencia liberadora que se burla de las leyes de la lógica, un supremo mimetismo de orden espiritual para conseguir tal objeto: pues si en el fenómeno zoológico denominado con aquella palabra lo que se consigue por medio de una semejanza es burlar a un determinado sér, del mismo modo, el poeta que afirma, rotundamente, que un capullo de rosa es un caracol marino, ejercita una suprema especie de mimetismo liberador y de orden estético, porque, sin duda, la imaginación es una fuerza anímica imponderable e íntimamente relacionada con la conciencia.

En tal virtud, la multiplicidad de temas que tan justamente ha sido señalada en la obra de Carrera Andrade, no es sino el corolario de lo que he enunciado. Tal es la ley que preside su doble mimetismo, la flexibilidad espiritual del artista.

Por ello, de su medula lírica surgen el poeta y el sudamericano cabal de este lado de América, de este costado en donde golpea el mar de Vasco Núñez de Balboa.

Es ese doble mimetismo poético que invade todo su Registro del mundo (y que hace de él una fosforescente carta geográfica) el que en contacto con el campo le hará exclamar:

\footnotetext{
Caminos hacia el cielo. Letanías polares lee el viento de noche en el libro del páramo. Se siente el paternal vaho de la torada y la bocina grita hacia el cielo estrellado, mientras en las haciendas alumbran como lunas los círculos de leche en los oscuros cántaros. La madrugada sale como un alma de monja a rodear los caminos. $Y$ da el cielo cristiano al campo que madruga desayuno de estrellas.
}

("Meseta")

$\mathrm{Y}$ aquella misma disposición animica, en contacto con el mar lleva su palabra por niveles tan opuestos, pero idénticos: 
En la nave de veinte cornetas

embarqué mi baúl de papagayos

hacia otro extremo de la tietra.

Ardia el alfabeto de las constelaciones.

Giraban gozosos los puertos niños

en el carrusel del horizonte.

Se amotinaron los mares

y los cuatro vientos

contra mi sueño almirante.

Ancla: Trébol de hierro.

Te arrojó el Capitán al continente antiguo.

$\mathrm{Vi}$ las torres cargadas con sus sacos de nubes

y las grúas cigüeñas

con su cesta en el pico.

("Boletín de viaje")

O, simplemente:

La lámpara de a bordo

salta como un gran pez

chorreando sobre el puente sa fulgor escamoso.

("Puerto a las 8")

Es un mismo suceso que se multiplica sin cesar. Es así cómo al llevar su elogio al río Guayas, de súbito, descubre que en él cabe la razón de todo un capítulo de su peregrinaje por el mundo:

Oh río, capitán de grandes ríos!

Es igual ta fluir ancho, incesante,

al de mi sangre llena de navíos

que vienen y se van a cada instante.

("Promesa del río Guayas")

Pero este fenómeno de la multiplicidad de temas, tiene como todo acontecimiento de orden artístico y por ello, humano, razones más profundas que dicen con el propio y personalísimo espíritu del poeta. En efecto, hay un área de su poesía, constituída por un nú- 
mero más reducido de poemas, en que prima por entero un sentimiento de carácter doméstico, familiar o íntimo. Su definición de la ventana es el mejor escudo de armas de esta cámara de su modalidad lírica:

La ventana nació de un deseo de cielo y en la muralla negra se posó como un ángel.

Es amiga del hombre y portera del aire.

("Biografía")

Es una línea poética que se ejercita a través de toda su obra. Una variante que ya adquiere, en uno de sus primeros libros, La hora de las ventanas iluminadas, toda su plenitud:

Cuando suenan las seis, la luz hace las pascuas.

A las habitaciones baja en lenguas de fuego

y revela a los hombres la venida de Dios

en la flor de la sopa y en el grave silencio.

Las ventanas se cierran y se abren los armarios.

Se vuelca en el mantel la cesta de los panes.

$Y$ los niños, sentados a la mesa casera,

ven posarse unas alas en la silla del padre.

("Pentecostés de la tarde")

En suma, en la poesía de Jorge Carrera Andrade, poeta autóctono por excelencia, el mundo externo ejerce una primacía apasionada. Por el hecho de ser la metáfora su arma eficaz, preferida, es la suya una poesía inimitable, personalísima, desprovista de todo elemento retórico. Estamos en presencia de un hecho poético sostenido, casi por entero, por el espíritu del poeta; por un espíritu exento de todo recurso decadente, ya que en ningún instante falta el júbilo, la euforia de un arte en pleno y verdadero equilibrio. Conviene señalar e insistir que en su adecuado vehículo constituído por el tropo nunca recurre al simple verbo, al mero lenguaje, para conseguir un resultado estético distinto... Por ello, a pesar de la modernidad de su obra y pese a la factura poco más o menos libre de los poemas que la integran, es el suyo un arte que tiende a lo clásico, 
en su más amplio sentido, ya que su oculto cauce dentro de lo contemporáneo persigue - como acabo de enunciarlo- vigor, eficacia y serenidad compatibles con la época en que ha sido creado, sin desdeñar la experiencia de ninguna de las escuela's del pasado.

Finalmente, como lo dijera en un principio, con su libro intitulado Registro del mundo, Jorge Carrera Andrade cierra su primera gran órbita poética, obra y órbita que le habilitan de sobra para ocupar una señalada cátedra entre los grandes poetas de la América del Sur.

\section{Antonio DE, UndurRaga}

\section{NOTAS}

1 Quito, Prensas de la Universidad, 1940.

2 La realidad y el deseo, p. 118. México, Editorial Séneca, 1940.

3 Residencia en la tierta, p. 116. Ediciones Ercilla, 1938, 39 edición.

4 Entre otros, el más joven del conjunto es. el poeta chileno Juvencio Valle, autor de El libto primero de Matgatita, tratado lítico sobre la selva y el folklore del Sur de Chile. Libro que, salvando épocas y estilos, pero no maestría, será en breve el Platero y yo de nuestra literatura.

5 "Recado sobre Pablo Neruda", El Mercurio, Santiago de Chile, 26 de abril de 1936.

6 La deshumanización del arte, p. 34. Santiago de Chile, Edición Cultura, 1932.

7 El profesor Freud, en su libro Totem y Tabú, para explicar esta palabra sigue la definición de la "Enciclopedia Británica", que dice: "La palabra 'Tabú' no designa en rigor, más que las tres nociones siguientes: a) El carácter sagrado (o impuro) de personas y objetos; b) la naturaleza de la prohibición que de este carácter emana; y c) la consagración (o impurificación) resultante de la violación de la misma. Lo contrario de tabú es en polinesio noa, esto es, lo corriente, ordinario y común".

8 Ortega y Gasset; obra citada, p. 35.

9 En el caso del tabú chileno mencionado, el pan adquiere para los niños un carácter sagrado al ser la cara misma de Dios $y$, en consecuencia, no puede ser malgastado, ni menos arrojado al suelo, por simple espíritu de juego. 
